〈연구논문(학술)〉

재생 방법에 따른 재생 폴리에스터사의 물성 변화

이선영 · 원종성 · 유재정 · 함완규 ${ }^{1} \cdot$ 이승구 $^{\dagger}$

충남대학교 유기소재 섬유시스템공학과, ${ }^{1}$ 한국생산기술연구원

\title{
Physical Properties of Recycled Polyester Yams According to Recycling Methods
}

\author{
Sun Young Lee, Jong Sung Won, Jae Jung Yoo, Wan-Gyu Hahm ${ }^{1}$ and Seung Goo Lee \\ BK21 FTIT, Department of Advanced Organic Materials \& Textile System Engineering, \\ Chungnam National University, Daejeon 305-764, Korea \\ ${ }^{1}$ Korea Institute of Industrial Technology
}

(Received: March 2, 2012/Revised: March 13, 2012/Accepted: March 23, 2012)

\begin{abstract}
The physical properties of recycled polyester yarns according to recycling methods were investigated. Virgin polyester draw texturized yarn(DTY), material-recycled(MR) polyester DTY and chemical-recycled(CR) polyester DTY were prepared. Surface morphology, thermal property, micro-structure and mechanical property of recycled polyester yarns were estimated. SEM-EDS analysis showed that the CR PET yarn had better crimp and more stable structure than MR PET yarn. Tm of the MR PET yarn was higher than that of the CR PET yarn. The intensity of the crystallization peak of the CR PET yarn was a little higher than that of the MR PET yarn. Tensile strength of the MR PET yarn was slightly higher than that of the CR PET yarn. Breaking elongation of the CR PET yarn was slightly higher than that of the MR PET yarn.
\end{abstract}

Keywords: PET yarn, recycling, material-recycled, chemical-recycled, thermal property, mechanical property

\section{1. 서 론}

최근 자연과 환경을 보호하려는 소비자의 의식과 관심이 고양됨에 따라 소비자 주도의 환경주의가 등 장하였다. 이에 따라 섬유패션산업에서도 환경친화적 인 고기능성 섬유를 개발하여 녹색 가치를 창출함으 로써 환경주의 소비자들의 요구에 대응하게 되었다.

일반적으로 폴리에스터는 가볍고, 고성능, 저비용 및 재활용성으로 인해 섬유시장에서 높은 시장점유 율을 차지해왔다. 그러나 폴리에스터는 생분해성이 좋지 않아 막대한 소비와 폐기로 인해 심각한 환경 문제를 야기하게 되었다. 그러므로, 폴리에스터로 인한 환경오염을 방지하고 에너지를 절감시키기 위 해서는 폴리에스터 섬유의 리싸이클 원천기술 확보 가 매우 중요하다 ${ }^{1)}$.

국내에서는 회수율이 $75 \%$ 로 높은 폐 폴리에스터 를 용융시켜 제조한 리싸이클 칩을 이용하여 물질 재생 폴리에스터를 개발, 양산하고 있으나 기능성 과 경제성면에서 개선의 여지가 많아 주로 저가의 포장재나 산업용 단섬유로 재활용되고 있다. 일본
에서는 2020년까지 기술정책전략의 섬유산업기술로 드맵에 친환경 기술을 핵심분야로 지정하여 첨단 친 환경 리싸이클 섬유제품 개발이 진행 중에 있다. 일본 $\mathrm{I}$ 사와 $\mathrm{T}$ 사에서 가수분해와 메탄올분해(methanolysis) 로 친환경 화학재생 폴리에스터섬유를 제조하였고 이를 이용하여 우수한 흡한 속건성과 세탁내구성을 갖는 신사복 셔츠를 개발한 바 있다 ${ }^{2)}$.

리싸이클 PET사에 대한 연구를 살펴보면, Chiachun 등 ${ }^{3)}$ 은 친환경 리싸이클 PET섬유를 이용한 복합재 료에 대한 연구를 수행하였다. Lei 등 ${ }^{4)}$ 은 화학재생 폴리에스터(R-PET)와 고밀도 폴리에틸렌 (HDPE)의 마이크로피브릴 복합소재(MFCs)를 제조하였고 상용 화제(PE-g-MA, SEBS-g-MA, E-GMA) 첨가가 결정 구조, 역학적 특성과 열적 특성에 미치는 효과에 대해 고찰하였다. Tawfik 등)은 에탄올아민을 이용 한 PET의 화학재생에 대해 연구하였고, Viana 등6) 은 촉매로 에틸렌글리콜(ethylene glycol)과 아연화 아세테이트(zinc acetate)를 이용하여 PET의 글리콜 분해(glycolysis)를 통한 화학적 재생에 대한 속도론 을 모델링하였다. Won 등그는 합성 PET와 물질재생

${ }^{\dagger}$ Corresponding author. Tel.: +82-42-821-7698; Fax.: +82-42-823-3736; e-mail: lsgoo@cnu.ac.kr

(c)2012 The Korean Society of Dyers and Finishers 1229-0033/2012-03/91-96 
PET로 만든 PET 시트에서 물질재생 PET의 함량을 결정하는 실험적 모델링 연구를 시도하였고, 물질재 생 PET가 광학적 성질, 열적 성질 및 역학적 성질 에 미치는 영향을 평가하였다. Upasani 등은 은 PET 플레이크의 화학적 리싸이클 반응자-교반자의 역할 및 고분자의 용융방사와 연신의 적합성을 검토하였 다. 지금까지 PET 섬유의 리싸이클 공정에 대한 연 구, 물질재생 $\mathrm{PET}$ 의 정량화 모델링, 화학재생 $\mathrm{PET}$ 의 해중합, 방사, 연신공정에 대한 연구가 되어 왔 는데 재생 $\mathrm{PET}$ 사에 대한 전반적인 물성에 관한 연 구는 거의 없으며, 개발된 물질재생 $\mathrm{PET}$ 사와 화학 재생 PET사 간의 물성 차이를 비교한 연구도 거의 없었다. 따라서 본 연구에서는 PET의 재생방법에 따 른 재생 폴리에스터사의 물성을 연구하기 위해 물 질재생 PET사와 화학재생 PET사를 이용하여 표면 형태, 열적 특성, 미세 결정구조 및 인장 특성 등 다양한 물리적 특성을 비교해 보고자 하였다.

\section{2. 실 험}

\section{1 시료}

본 연구에서 사용된 시료는 다음과 같다. 합성(Virgin) PET Draw Texturized Yarn (DTY) (Huvis, 75d/72f), 물질재생 PET DTY사 (Huvis, 75d/36f), 화학재생 PET $\mathrm{DTY}$ 사 (Huvis 75d/36f) 시료 3종을 분석에 사용하 였다. 시료의 섬도와 수평균분자량 및 고유점도는 Table 1에 제시된 바와 같다

\section{2 물성 실험}

\subsection{1 실의 표면 형상}

주사전자현미경(SEM-EDS, S-4700, Hitachi)를 이 용하여 50 초간 백금으로 코팅 후 실의 표면 구조를 50 배로 관찰하였고, 실의 불순물을 분석하기 위해 9000 배로 관찰하면서 SEM-EDS로 원소분석을 실시 하였다.

\subsection{2 실의 권축 회복률}

KS K 0419의 방법에 따라 실험하여 다음 식에 따라 권축회복률을 구하였다.

$$
\text { Crimp Recovery }(\%)=\frac{a-b}{a} \times 100
$$

$\mathrm{a} ; 0.002 \mathrm{~g} / \mathrm{D}$ 하중에 상당하는 고리와 $0.1 \mathrm{~g} / \mathrm{D}$ 의 하중에 상당하는 추를 가하였을 때의 실 타래 길이 $(\mathrm{mm})$

b ; $0.1 \mathrm{~g} / \mathrm{D}$ 하중에 상당하는 추를 제거하였을 때의 실 타래 길이 $(\mathrm{mm})$

\section{2 .3 실의 열적 특성}

시차주사열량계(DSC)를 이용하여 질소 기류 하에 서 상온에서 $300^{\circ} \mathrm{C}$ 까지 승온속도 $10^{\circ} \mathrm{C} / \mathrm{min}$ 로 승온 하면서 실의 열적 특성을 측정하였다. 열중량분석기 (TGA)를 이용하여 질소 기류 하에서 상온에서 $600^{\circ} \mathrm{C}$ 까지 $10^{\circ} \mathrm{C} / \mathrm{min}$ 으로 승온하면서 실의 열적 거동을 측 정하였다.

\subsection{4 실의 결정구조}

X-선 회절 장치(XRD, RINT2000 Wide angle goniometer)를 이용하여 power $40 \mathrm{kV}, 100 \mathrm{~mA}$ 로 scan speed $1 \% \mathrm{~min}$ 으로 측정범위는 $5^{\circ}$ 에서 $60^{\circ}$ 까지 $\mathrm{X}$ 선을 조사 하여 실의 미세 결정구조를 분석하였다.

\section{2 .5 실의 역학적 특성}

$\mathrm{KS} \mathrm{K} \mathrm{0412의} \mathrm{방법에} \mathrm{의해} \mathrm{로드셀의} \mathrm{하중} 10.0 \mathrm{gf}$, 인장속도 $500 \mathrm{~mm} / \mathrm{min}$, 파지거리 $500 \mathrm{~mm}$ 로 하여 실의 인장강도와 절단신도를 측정하였다.

\section{3. 결과 및 고찰}

\section{1 실의 표면 분석}

재생 방법에 따른 재생 PET DTY사의 표면형상의 차이를 조사하기 위해 SEM-EDS분석을 실시하였고 결과를 Fig. 1에 제시하였다. DTY 가공된 합성(Virgin) $\mathrm{PET}$ 사와 물질재생 $\mathrm{PET}$ 사, 화학재생 $\mathrm{PET}$ 사 모두 에서 권축이 발생됨을 확인할 수 있었다. 물질재 생 PET DTY사와 화학재생 PET DTY사의 권축의 양상을 비교해 보면, 화학재생 PET사의 경우, 물 질재생 $\mathrm{PET}$ 사보다 권축의 파상 곡률이 더 크고 더 벌키하게 잘 형성되어 있는 것을 볼 수 있다. 이러 한 결과는 재생 방법에 기인한 것으로서 물질재생 PET 섬유는 화학재생 PET섬유보다 분자량 더 크고 중합

Table 1. Characteristics of PET yarn

\begin{tabular}{|c|c|c|c|}
\hline Parameter & Fineness(denier) & $\begin{array}{c}\text { Number average } \\
\text { molecular weight }\left(M_{n}\right)\end{array}$ & Intrinsic viscosity(I.V.) \\
\hline Virgin PET DTY & 77.8 & 17,822 & 0.608 \\
\hline Material-recycled PET DTY & 74.5 & 18,396 & 0.620 \\
\hline Chemical-recycled PET DTY & 76.3 & 16,275 & 0.573 \\
\hline
\end{tabular}


도가 더 크기 때문에 PET사의 DTY 가공시 열에 대 한 저항성도 더 커지게 된다. 또한, 물질재생 PET섬 유는 폐 PET를 회수하여 세척, 파쇄, 건조, 재용융 및 펠렛화를 거쳐 만들기 때문에 이물질의 제거가 곤란하여 섬유 내 불순물을 포함하고 있다. 이러한 이유로 재생 PET사의 DTY가공의 효과가 감소하게 되어 물질재생 PET사는 화학재생 PET사보다 권축 발생이 덜 이루어진 것으로 사료된다.

물질재생 PET DTY사와 화학재생 PET DTY사의

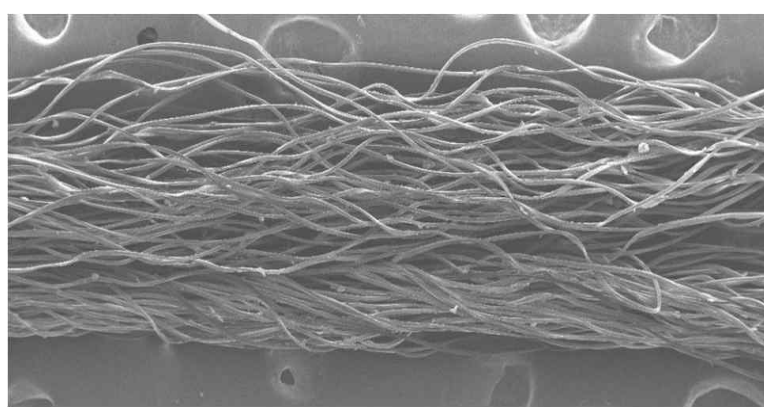

(a)

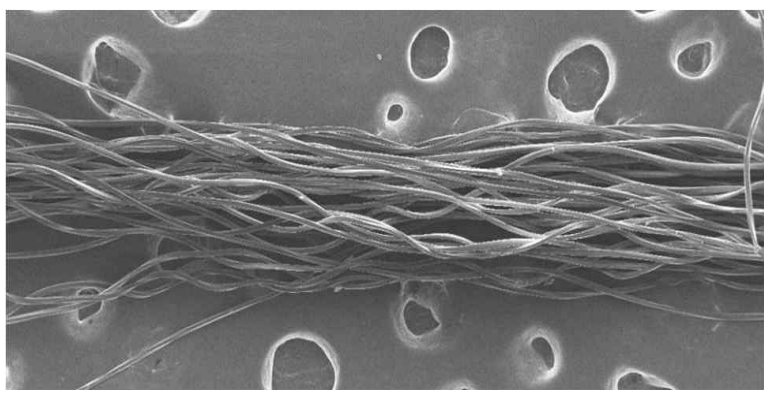

(b)

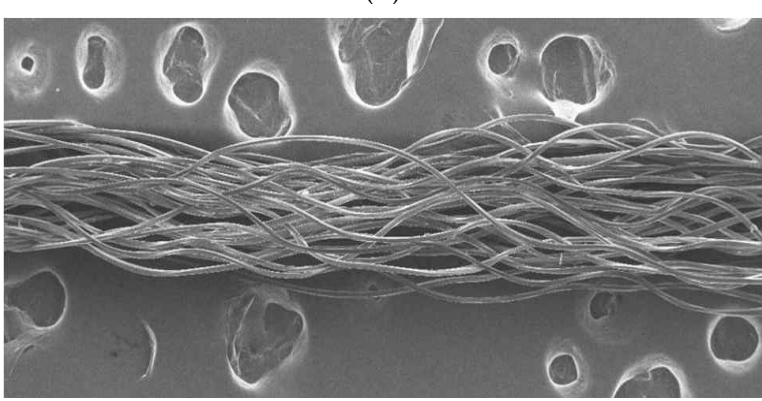

(c)

Fig. 1. SEM morphology of PET DTY according to recycling methods.
(a) Virgin PET DTY
(b) Material-recycled PET DTY

(c) Chemical-recycled PET DTY
표면형상의 결과에서 권축 발생 정도의 차이를 정 량적으로 살펴보기 위해서 실의 권축 회복률 시험 을 해보았고, 그 결과를 Table 2에 제시하였다. 권 축 회복률은 합성 $\mathrm{PET}$ 사 < 물질재생 $\mathrm{PET}$ 사 < 화 학재생 PET사 순으로 증가하였다. 물질재생 PET사 의 권축 회복률은 화학재생 PET사보다 더 작게 나 타났다. 이것은 Fig. 1에서 물질재생 PET사의 권축 이 화학재생 PET사의 권축보다 덜 굴곡되어 있는 표면형상 결과를 뒷받침한다.

물질재생 PET사와 화학재생 PET사의 열적 거동 의 차이를 살펴보기 위해 $\mathrm{DSC}$ 를 이용하여 분석하 였으며, 그 결과를 Fig. 2에 제시하였다. 재생 방법 에 따른 재생 $\mathrm{PET}$ 사의 열적 성질을 보면, $\mathrm{Tg}$, 결정 화 온도, 융점과 융해열에서 재생 PET사간의 다소 차이를 보이는 것으로 나타났다.

Fig. 2를 보면, 합성 $\mathrm{PET}$ 사의 $\mathrm{Tg}$ 가 $78.3^{\circ} \mathrm{C}$ 이고, 결정화 피크는 $112.65^{\circ} \mathrm{C}$ 이며, 융점은 $253.71^{\circ} \mathrm{C}$ 로 나 타났다. 물질재생 $\mathrm{PET}$ 사의 $\mathrm{Tg}$ 와 결정화 피크가 뚜 렷하게 잘 나타나지 않았으며, 융점은 $258.98^{\circ} \mathrm{C}$ 로 나타났다. 화학재생 PET사는 합성 $\mathrm{PET}$ 사와 달리 $\mathrm{Tg}$ 와 결정화 피크가 관찰되지 않았으며, 융점은 $253.77^{\circ} \mathrm{C}$ 로

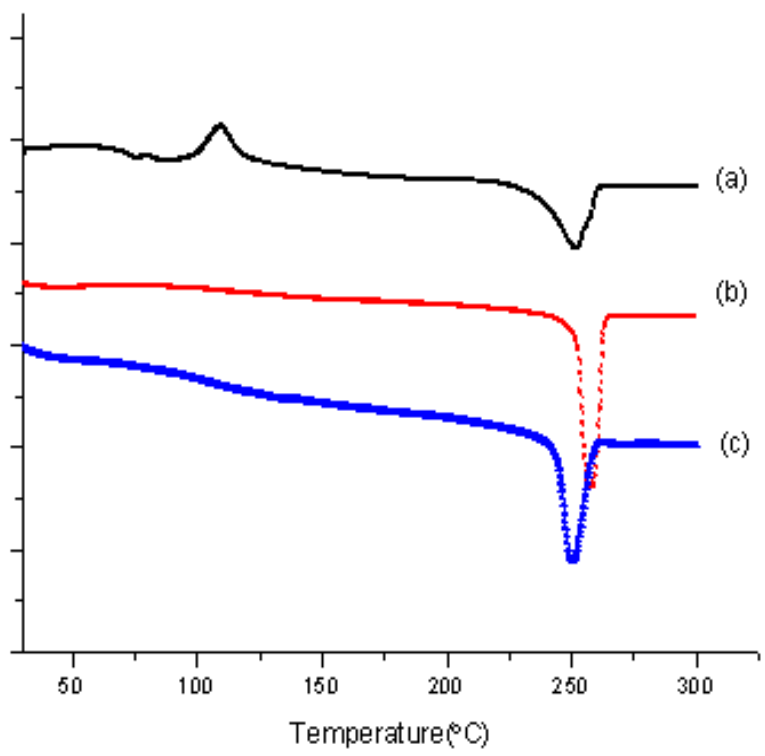

Fig. 2. DSC scans of PET yarns according to recycling methods.
(a) Virgin DTY
(b) Material-recycled DTY
(c) Chemical-recycled DTY

Table 2. Crimp recovery of PET DTY according to recycling methods

\begin{tabular}{|c|c|c|c|}
\hline PET yarn & Virgin DTY & Material-recycled DTY & Chemical-recycled DTY \\
\hline Crimp recovery(\%) & 6.82 & 7.50 & 10.32 \\
\hline
\end{tabular}


다소 낮게 나타났다. 융해열을 살펴보면, 합성 PET사 는 $44.06 \mathrm{~J} / \mathrm{g}$, 화학재생 PET사는 $50.53 \mathrm{~J} / \mathrm{g}$, 물질재생 $\mathrm{PET}$ 사는 $56.24 \mathrm{~J} / \mathrm{g}$ 으로 나타났다.

열분석 결과를 보면, 물질재생 PET사와 화학재생 $\mathrm{PET}$ 사의 융점과 융해열에서 약간의 차이가 관찰되 었다. $\mathrm{Tg}$ 와 결정화 피크의 경우, 합성 $\mathrm{PET}$ 사에서 만 나타났고 물질재생 PET사나 화학재생 PET사에 서는 보이지 않았다. 융점은 화학재생 PET사 $\lesssim$ 합성 PET사 < 물질재생 PET사 순으로 높게 나타 났다.

융점은 물질재생 PET사의 융점은 화학재생 PET 사보다 약간 높았고, 융해열도 역시 물질재생 PET 사가 화학재생 PET사보다 더 높게 나타났다. 이는 물질재생 $\mathrm{PET}$ 섬유의 경우 고상중합법으로 제조하 기 때문에 중합도가 섬유로 이용되는 PET보다 더 높고, 폐PET를 회수하여 세척, 파쇄, 건조, 재용융 및 펠렛화를 거쳐 만들기 때문에 이물질 제거가 곤 란하여 불순물을 포함하고 있어서 $\mathrm{Tg}$ 와 결정화 피 크가 덜 명확하게 나타난 것으로 사료된다. 또한 화학재생 PET사의 경우 해중합과 재중합 시에 사 용되는 많은 촉매의 영향으로 인하여 $\mathrm{Tg}$ 와 결정화 피크가 명확하지 않은 것으로 사료된다.

물질재생 PET사와 화학재생 PET사의 열분해와 열분해 후 중량감소율의 차이를 살펴보기 위해 TGA 분석을 실시하였고, 그 결과를 Fig. 3에 나타내었 다. 합성 $\mathrm{PET}$ 사, 물질재생 $\mathrm{PET}$ 사와 화학재생 $\mathrm{PET}$ 사 모두 $400^{\circ} \mathrm{C}$ 부근에서 급격한 중량 감소를 나타 내었다.

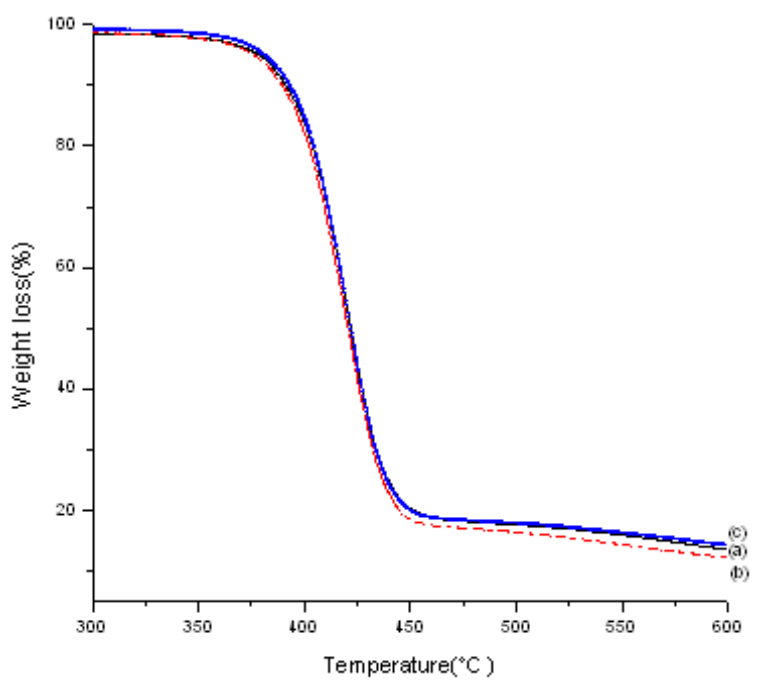

Fig. 3. TGA curves of PET yarns according to recycling methods.
(a) Virgin DTY
(b) Material-recycled DTY
(c) Chemical-recycled DTY

각각의 잔존량을 보면, 합성 PET사 $13.46 \%$ 이었고, 화학재생 PET사는 $14.25 \%$, 물리재생 PET사 $12.08 \%$ 순으로 나타났다. 본 실험에 사용된 재생 $\mathrm{PET}$ 사와 합성 PET사 모두 $400^{\circ} \mathrm{C}$ 부근에서 열분해가 시작되었 음을 알 수 있었고, 열분해 후 잔존량은 $12-14 \%$ 범 위였다. 그러나, 열분해가 급격히 일어나는 $400^{\circ} \mathrm{C}$ 이상의 고온 범위에서의 열거동을 자세히 검토해 보면, 합성 PET사, 물질재생 PET사, 화학재생 PET 사간의 근소한 차이를 볼 수 있다. 물질재생 PET 사는 화학재생 $\mathrm{PET}$ 사보다 중량감소율이 더 크고, 열분해후 잔존량이 더 작았다. 화학재생 PET사는 합성 PET사와 거의 비슷하며, 물질재생 PET사보다 열에 대해 다소 안정적인 열적 거동을 보여주고 있 음을 알 수 있다.

$\mathrm{PET}$ 의 재생방법에 따른 재생 PET사의 결정성을 파악하기 위해 합성 PET사, 물질재생 PET사와 화 학재생 $\mathrm{PET}$ 사를 $\mathrm{XRD}$ 로 분석하였고, $\mathrm{XRD}$ 패턴과 $2 \theta$ 값을 Fig. 4에 제시하였다. XRD에 의한 분석 결 과, PET사의 재생 방법에 따라 결정 패턴은 유사 하고 결정화도의 차이도 거의 나타나지 않았다. 불 규칙하고 평평하지 않은 형태의 PET DTY사를 대 상으로 $\mathrm{XRD}$ 를 이용하여 매우 명확한 분석결과를 얻기에는 한계가 있다고 생각된다. $2 \theta=14.05$ 부근 과 $2 \theta=16.89$ 부근에서 결정피크의 강도를 보면, 물 질재생 PET사 < 화학재생 PET사 < 합성 PET사 순 으로 미미하게 증가하는 경향을 볼 수 있었다.



Fig. 4. XRD patterns of PET yarns according to recycling methods.
(a) Virgin DTY
(b) Material-recycled DTY
(c) Chemical-recycled DTY 
재생방법에 따른 재생 PET사의 역학적 성질을 비교하기 위해 세 종류의 PET사의 인장강도와 절 단신도를 측정하였고, 그 결과를 Fig. 5와 Fig. 6에 나 타내었다. Fig. 5를 보면, 인장강도는 화학재생 PET사 $<$ 합성 PET사 ミ 물질재생 PET사 순으로 증가하는 것으로 나타났다. 물질재생 PET사는 합성 PET사에 비해 순도가 떨어지지만, 중합도와 분자량이 높기 때문에 합성 PET사의 강도와 유사한 것으로 생각된 다. 그런데, 화학재생 PET사는 물질재생 PET사와 합성 PET사에 비해 더 낮은 강도를 나타내었다. 이 는 해중합시 촉매제가 실 표면이나 내부에 미량 잔 류되어 이로 인해 화학재생 $\mathrm{PET}$ 사의 인장강도가 합성 PET사보다 더 낮아진 것으로 생각된다.

SEM-EDS에 의한 원소분석을 실시한 결과, 합성 $\mathrm{PET}$ 사에서는 $\mathrm{Ti}$ 이외 다른 금속원소는 검출되지 않 았는데 반해 물질재생 PET사나 화학재생 PET사에 서는 $\mathrm{Ti}$ 와 $\mathrm{Si}$ 원소도 미량 포함되어 있는 것으로 나타났다. 화학재생 PET사의 강도는 합성 PET사보 다 낮은 것으로 보이며, 재생 PET사 내부에 잔류 된 촉매제나 불순물의 정제기술을 통해 사 강도를 향상시킬 수 있을 것으로 생각된다.

Fig. 6에서 절단신도는 물질재생 PET사 $\lesssim$ 화학재

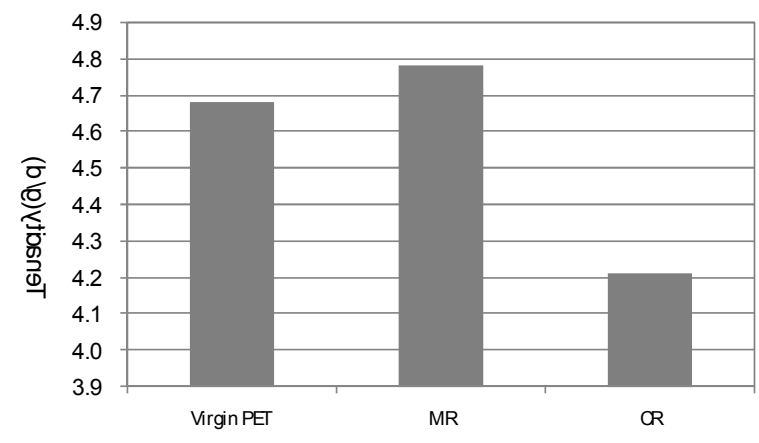

PET DTY

Fig. 5. Tenacity of PET DTY according to recycling methods.

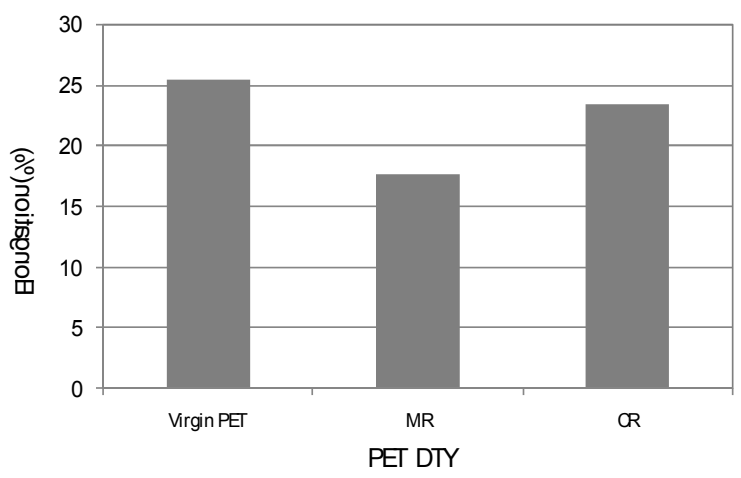

Fig. 6. Elongation of PET DTY according to recycling methods.
생 $\mathrm{PET}$ 사 $\lesssim$ 합성 $\mathrm{PET}$ 사로 증가하는 것으로 나타 났다. 절단신도는 화학재생 PET사는 물질재생 PET 사보다 약간 더 높았고 합성 PET사와 유사한 신도 를 나타내었다. 이는 고상중합체로부터 재생된 물 질재생사의 경우 중합도가 높고 stiff한 특성을 가 지고 있기 때문으로 사료된다.

\section{4. 결 론}

본 연구에서는 재생 방법에 따른 재생 폴리에스 터사의 물리적 특성 변화를 분석하고자 하였다. 시 료로는 물질재생 방법과 해중합을 통한 화학재생 방법을 사용하여 제조된 재생 폴리에스터 DTY사 를 이용하였고, 재생 PET사의 표면형상, 열적 성질, 결정구조와 인장 성질을 측정하여 합성(Virgin) PET 사의 물성과 비교, 분석하였으며 그 결과는 다음과 같다.

1. 재생 방법에 따른 재생 PET사의 표면형상을 $\mathrm{SEM}$ 과 권축회복률 시험에 의해 분석한 결과, 화 학재생 PET사가 물질재생 PET사보다 DTY 가공 에 의해 권축이 더 벌키하게 잘 형성된 것을 확 인하였다.

2. 재생 방법에 따른 재생 PET사를 열분석한 결과, 물질재생 PET사의 Tm은 합성 PET사보다 약간 높고, 화학재생 PET사의 Tm은 합성 PET사에 비 해 약간 낮게 나타났다. 열분해 후 중량 감소율 과 잔존량의 경우, 물질재생 $\mathrm{PET}$ 사가 합성 $\mathrm{PET}$ 사와 화학재생 $\mathrm{PET}$ 사보다 더 작게 나타났다.

3. 재생 방법에 따른 재생 PET사의 미세 결정구조 를 $\mathrm{XRD}$ 에 의해 분석한 결과, 결정화 패턴은 유 사하였으나, 결정화 강도는 물질재생 $\mathrm{PET}$ 사 < 화학재생 PET사 < 합성 PET사 순으로 다소 증 가하는 것으로 나타났다.

4. 재생 방법에 따른 재생 PET사의 역학적인 특성 을 분석한 결과, 인장강도는 화학재생 $\mathrm{PET}$ 사 < 합성 $\mathrm{PET}$ 사 $\lesssim$ 물질재생 $\mathrm{PET}$ 사 순으로 증가하 는 것으로 나타났다. 절단신도는 물질재생 PET 사 $\lesssim$ 화학재생 $\mathrm{PET}$ 사 $\lesssim$ 합성 $\mathrm{PET}$ 사로 증가하 는 것으로 나타났다.

$$
\text { 감사의 글 }
$$

본 연구는 산업원천기술개발사업(과제번호10035180) 의 지원으로 수행되었음.

\section{참고문헌}

1. S. H. Kim, W. G. Hahm, S. Y. Park, K. S. Lee, and H. J. Koo, Development of Environmentally- 
Friendly Recycled Textiles, Fiber Technology and Industry, 12, 1-10(2010).

2. Ministry of Knowledge Economy, "Development of Environmentally-Friendly Recycled Textiles", The First Annual Report, Ministry of Knowledge Economy, 2011.

3. T. Chiachun, A. Ishak and H. Muichin, Characterization of Polyester Composites from Recycled Polyethylene Terephthalate Reinforced with Empty Fruit Bunch Fibers, Materials \& Design, 32(8), 4493-4501(2011).

4. Y. Lei, Q. Wu, and Q. Zhang, Morphology and Properties of Microfibrillar Composites Based on Recycled Polyethylene Terephthalate and High Density Polyethylene, Composite, 40, 904-912(2009).

5. M. E. Tawfik and S. B. Eskander, Chemical Recycling of Polyethylene Terephthalate Waste Using Ethanolamine, Sorting of End-Products, Polymer Degradation and Stability, 95(12), 187-194(2010).

6. M. E. Viana, A. Riul, G. M. Carvalho, A. F. Rubira and E. C. Muniz, Chemical Recycling of PET by Catalyzed Glycolysis; Kinetics of Heterogenous Reaction, Chemical Engineering J., 173(1), 210-219 (2011)

7. J. P. Won, C. G. Park, S. J. Lee and J. W. Kang,
Bonding Characteristics of Recycled Polyethylene Terephthalate (PET) Fibers Coated with Maleic Anhydride Grafted Polypropylene in Cement-Based Composite, J. App. Polymer Science, 121(4), 19081915(2011).

8. P. S. Upasani, A. K. Jain and N. Save, Chemical Recycling of PET Flakes into Yarn, J. App. Polymer Science, 123(1), 520-525(2012).

9. W. G. Hahm, J. H. Yoo, S. Y. Lee, J. S. Won, and S. G. Lee, Study on Structure Evolution of Chemical Recycled PET Fiber in High-Speed Melt Spinning, Proc. 2nd Kor. Text. Conf., Vol.44, p.35, 2011.

10. J. Scheirs, "Polymer Recycling: Science, Technology, and Applications", John Wiley \& Sons, England, p.125, 1998.

11. H. K. Kang, Y. S. Kim and Y. A. Son, Preparation and Characterization of Stretch Fabric : Shrinkage and Elasticity Properties, Textile Coloration and Finishing(J. of Korean Soc. Dyers \& Finishers), 22(2), 173-180(2010)

12. M. S. Park, The Mechanical Properties of New Worsted Wool-like Fabrics Using Latent Yarns, Textile Coloration and Finishing(J. of Korean Soc. Dyers \& Finishers), 22(4), 233-240(2010). 